\title{
Pragmatic randomized trial of antenatal intervention to prevent post-natal depression by reducing psychosocial risk factors
}

\author{
T. S. BRUGHA, ${ }^{1}$ S. WHEATLEY, N. A. TAUB, A. CULVERWELL, T. FRIEDMAN, \\ P. KIRWAN, D. R. JONES AND D. A. SHAPIRO \\ From the Section of Social and Epidemiological Psychiatry, Department of Psychiatry, Department of \\ Epidemiology and Public Health and Department of Obstetrics and Gynaecology, University of Leicester; and \\ Psychological Therapies Research Centre, School of Psychology, University of Leeds
}

\begin{abstract}
Background. Social support theory and observational risk factor studies suggest that increased antenatal psychosocial support could prevent post-natal depression. We used empirical knowledge of risk and protective factors for post-natal depression not employed previously in order to develop and evaluate an antenatal preventive intervention.
\end{abstract}

Methods. We conducted a pragmatic randomized controlled trial in antenatal clinics. We screened 1300 primiparous women and 400 screened positive, 69 screen-positive women were untraceable or not eligible. Of 292 women who completed baseline assessment, 209 consented to randomization, of these 190 provided outcome data 3 months post-natally. 'Preparing for Parenthood', a structured antenatal risk factor reducing intervention designed to increase social support and problem-solving skills, was compared with routine antenatal care only. We compared the percentage depressed at 3 months after childbirth using the self-completion General Health Questionnaire Depression scale and Edinburgh Post-natal Depression Scale (EPDS), and the Schedules for Clinical Assessment in Neuropsychiatry a systematic clinical interview.

Results. Assignment to the intervention group did not significantly impact on post-natal depression (odds ratio for GHQ-Depression 1.22 (95\% CI $0.63-2.39), P=0.55)$ or on risk factors for depression. Forty-five per cent of the intervention group women attended sufficient sessions to be likely to benefit from intervention if effective. Attenders benefited no more than non-attenders.

Conclusions. Prevention services targeting post-natal depression should not implement antenatal support programmes on these lines until further research has demonstrated the feasibility and effectiveness of such methods. The development of novel, low cost interventions effective in reducing risk factors should be completed before further trial evaluation.

\section{INTRODUCTION}

Depression is an important worldwide public health issue (Murray \& Lopez, 1997) as disabling as a chronic medical condition such as diabetes (Wells et al. 1993). Women are more likely to develop depression (Paykel \& Priest, 1992). Women are at increased risk of developing a first

1 Address for correspondence: Professor T. S. Brugha, Section of Social and Epidemiological Psychiatry, Department of Psychiatry, University of Leicester, Academic Unit. Brandon Mental Health Unit. Leicester General Hospital, Gwendolen Road, Leicester LE5 4PW. episode of clinical depression within 3 months of childbirth (Brugha et al. 1998a). Post-natal depression can have deleterious effects on the family and child development (Murray et al. 1996). Efficacy studies of treatment to prolong depression remission and prevent relapse show the prognosis is often poor (Klerman \& Weissman, 1992). Reducing under-detection (Paykel \& Priest, 1992) and achieving better outcomes (Brugha, 1995a) requires highly skilled and motivated staff input and unusually high patient compliance. Investigation of effective 
methods of preventive action, particularly in mothers after childbirth, is thus merited.

Well controlled randomized trials of preventive interventions for post-natal depression have not been conducted (Holden, 1994; Mrazek \& Haggerty, 1994; Paykel \& Jenkins, 1994). However, the feasibility of screening and intervening during pregnancy has been demonstrated (Elliott et al. 1988; Holden, 1994). Elliott described how regular antenatal and post-natal educational and support group meetings (Elliott et al. 1988) reduced the prevalence of post-natal depression. Other attempts to conduct prevention trials used inadequate randomization (Gordon \& Gordon, 1960) or suffered from very low attendance (Stamp et al. 1995). Limited evidence that depression is preventable has been claimed in one published randomized trial in adolescents (Clarke et al. 1995). Additional antenatal psychosocial support for women is often strongly advocated 'as per right' and is widely believed to be of benefit (Corcoran, 1997) to the psychological well-being of the mother and the family. In a similarly optimistic vein, advice that informal social support can reduce the risk of post-natal depression (Department of Health, 1999) has been given, although based on evidence of the effectiveness of "clearly defined treatment as opposed to prevention of postpartum depression' in post-natally depressed mothers (Ray \& Hodnett, 1999).

The causes of depression are unknown. In non-experimental prospective studies poor antenatal social support to the mother is a significant predictor of post-natal depression (Paykel et al. 1980; Cutrona, 1989; O’Hara \& Swain, 1996; Brugha et al. 1998 a). Lack of (expected) support from the pregnant woman's mother and/or partner, not being able to talk openly with someone who had shared and understood the same problems and not being offered support without having to ask for it, predicted post-natal depressive symptoms (Brugha et al. 1998a) assessed by the depression scale of the General Health Questionnaire (Surtees \& Miller, 1990). Companionship and belonging to a group of similar others significantly predicted reduced post-natal depression (Cutrona, 1989). Studies looking at the effect of prior increased levels of depression also show that this is a highly significant predictor of subsequent cases of depression (O'Hara \& Swain, 1996; Brugha et al. 1998). Such evidence provides a theoretical basis for predicting that individual level improvements in social support and coping combined with reduction in current depressive symptoms will reduce the risk of later development of depression.

Risk reduction, including the strengthening of protective factors, is the best available theoretical model for guiding interventions at the individual level to prevent mental disorders (Mrazek \& Haggerty, 1994), but has not been applied to post-natal depression (Holden, 1994; Mrazek \& Haggerty, 1994; Brugha, 1995b). To increase protective factors antenatally we adapted a parental-support-enhancing intervention programme (Kirkham, 1993). We hypothesized that women at increased risk of post-natal depression randomized to receive the intervention antenatally would be less likely to be depressed at 3 months post-natally, a time of increased incidence (Brugha et al. 1998 a ; Cooper et al. 1988).

\section{METHOD}

Mothers in their first pregnancy attending the Leicester General Hospital antenatal clinics who were identified, by screening, to be at increased risk of post-natal depression were randomized to receive a brief, structured intervention or standard antenatal care only. The prevalence of symptoms of post-natal depression at 3 months after childbirth was compared in 'treated' and control group mothers.

Each woman had to be at least 16 years of age at booking for obstetric care in a first pregnancy that she planned to continue to full-term, residing within reasonable travelling distance of the hospital, capable of understanding and completing screening questionnaires in English and of giving written, informed consent. A screening questionnaire 'Pregnancy and You', was developed using earlier cohort data from the same population (Brugha et al. 1998a). The presence of any one of six depression items that indicated antenatal depression on a modified General Health Questionnaire (GHQ-D) (Surtees \& Miller, 1990) was the strongest predictor of post-natal depression. All potentially eligible women willing to complete the questionnaire did so between 12 and 20 weeks of gestation. 
- Acknowledgement and discussion of social and emotional problems of pregnancy

- Information about post-natal depression, its identification, sources of help and the importance of social support

- Learning ways to develop, use and maintain support skills

- Learning and practising problem solving skills, especially in relation to risk factors

- Identification and exploration of unhelpful thoughts and beliefs about pregnancy and motherhood.

Fig. 1. Key elements and techniques used in preparing for parenthood (PFP) intervention (Brugha et al. 1998b).

The intervention 'Preparing for Parenthood' (PFP), was based on an international, collaborative review of the social support intervention literature (Brugha, 1995b). At the time there was no detailed manual describing such interventions for future parents. Therefore, PFP was developed by modifying a group intervention used for parents of handicapped children (Kirkham, 1993), which had been reported to be clinically effective in reducing depression at 2 year follow-up in a randomized treatment study. It was clearly described in an intervention manual and addressed risk and protective factors for later depression including low levels of social support and high antecedent levels of depression.

PFP consists of six structured 2 hour long, weekly antenatal classes, preceded by an initial introductory meeting with the participant and her partner (Wheatley et al. 2000). PFP ends with a post-natal reunion class when the babies are about 8 weeks old. PFP is fully documented in a manual including checklists and process forms for completion by course participants and course leaders (Brugha et al. 1998b). The key elements and techniques are summarized in Fig. 1. PFP draws on established psychological models for tackling depression using cognitive and problem solving approaches (Hawton et al. 1990) together with emerging models for enhancing social support (Brugha, 1995c; Parry, 1995) at an individual level.

General education was given rather than formal lectures; each group included three or four exercises in which women were encouraged to share and discuss principles and topics using personal examples of their own. There were two role-plays. A problem-solving model and other key constructive behaviours were reinforced regularly and women were encouraged to prac- tice new skills between sessions. The group was expected to provide emotional support, but with the intention of encouraging participants to learn to acknowledge and make better effective use of opportunities for receiving emotional support in the future (Parry, 1995).

Nurses and occupational therapists, with extensive experience in hospital and community general psychiatry, but without specialist experience in psychological interventions, were selected and trained to conduct PFP and to attend supervision sessions; they were not involved in any way in intervention allocation or in the research assessments. Two female course leaders, one of whom was a parent, were present at all sessions of each course group. The woman's partner or 'significant other' was encouraged to attend session 3, for which a male course leader was present. PFP classes commenced soon after the 28th week of gestation. Women in a pilot group beginning before the 24th week felt less committed and less able to take time off work; women felt physically less well in a pilot study beginning after 30 weeks that was also difficult to schedule alongside parentcraft classes. Course registration ranged from 8 to 16 women per group depending on numbers screening positive, motivation, consent and the need to schedule courses ahead of time. Women not attending any sessions were sent an abbreviated set of PFP handouts including information on post-natal depression symptoms and social support. A participant missing a session without an explanatory message was sent the session handouts. After two consecutive unexplained absences, a participant was no longer sent missed session handouts.

Depression at 3 months after childbirth, was assessed with self-completion questionnaires: 
the modified GHQ-D (Surtees \& Miller, 1990); the Edinburgh Post-natal Depression Scale (EPDS) (Cox et al. 1987) and a semi-structured clinical interview, the Schedules for Clinical Assessment in Neuropsychiatry (SCAN) (Wing et al. 1990). The primary outcome was two or more symptoms of depression present on GHQD. Depression at 3 months measured otherwise had status secondary to this.

The original power calculation, based on poorly-evidenced assumptions, required at least 60 patients in each group for a power of 0.8 to detect a relative reduction of $66 \%$ (Elliott et al. 1988 ) in the proportion of GHQ-D cases from 0.35 (Brugha et al. 1998 a) to $0 \cdot 12$ at the $5 \%$ significance level. During the course of the trial it proved possible to recruit approximately 100 patients per group.

Screen positive women were seen at 20 to 24 weeks gestation for a baseline interview covering symptoms (Cox et al. 1987; Surtees \& Miller, 1990) and risk factors including, social support networks (Brugha et al. 1987) and pregnancyrelated support (Brugha et al. 1998a), threatening life events (Brugha et al. 1985; Brugha \& Cragg, 1990) including key pregnancy events (Barnett et al. 1983), problem-solving style (Heppner \& Petersen, 1982), locus of control (Labs \& Wurtele, 1986), social functioning (Meltzer et al. 1995) and satisfaction with housing (Wheatley, 1998).

A leaflet explaining PFP was introduced by the research interviewer and times and arrangements for the classes explained. Women were asked to consider this for 24 to 48 hours. It was explained that, if interested, entry to the class would depend on a 'toss of a coin' (i.e. randomization) when re-contacted.

Following the baseline interview computerized stratified randomization, using minimization (Evans et al. 1990) (with stochastic element) on three prognostic factors: level of social support, screen GHQ-D and ethnic group, was used by the research interviewer to allocate half the consenting women to intervention and half to control. The women were not contacted further by any research interviewer until the post-natal outcome assessment, when they were asked not to reveal whether they had been invited to attend PFP sessions.

After each follow-up interview the researcher recorded which group she thought the respon- dent had been allocated to, based on her observations during the outcome assessment. The allocation code was not broken until completion of the fieldwork and primary analyses. Assessment, randomization and intervention stages, including three PFP courses, were all piloted over a 6-month period, during which course leaders gained experience in conducting sessions.

We compared the proportions of subjects with depression (defined as GHQ-D score $\geqslant 2$ ) between the two randomized groups, by intention to treat. This was adjusted for the 3 factors used in minimization, using logistic regression. Results are presented as odds ratios with $95 \%$ confidence intervals and $P$ values. Odds ratios for a probable case of depression, as indicated by an EPDS score $\geqslant 11$, and for the SCAN interview using ICD-10 criteria for depressive disorder (World Health Organization Division of Mental Health, 1990) are also presented. These analyses were repeated without adjustment. Social support (Brugha et al. 1987) and other secondary outcome risk and protective factors (Brugha et al. 1998b), which the intervention aimed to improve, were also assessed at 3 months and compared between women randomized to the two groups. Additional secondary analyses examined the effects of risk and protective factors on outcome. The primary and other outcomes were also examined in a preplanned analysis of attender and non-attender subgroups of the intervention group. We also carried out a proportional hazards model (survival analysis) (Cox, 1972) modelling time to onset between childbirth and 3 months. Statistical significance was assessed at the 5\% level.

\section{RESULTS}

Participant flow from screening through to the outcome measurements 3 months after childbirth is described in Fig. 2 and baseline characteristics of the two randomized groups are shown in Table 1. A total of 1300 women completed antenatal screening. Fewer than 5\% of women refused screening. Thirty-six screen positive women were untraceable and 33 were non-eligible for inclusion, mainly due to lack of spoken English or to advanced gestation preventing them from taking part fully. Thirty-nine refused the trial baseline interview. Of the 


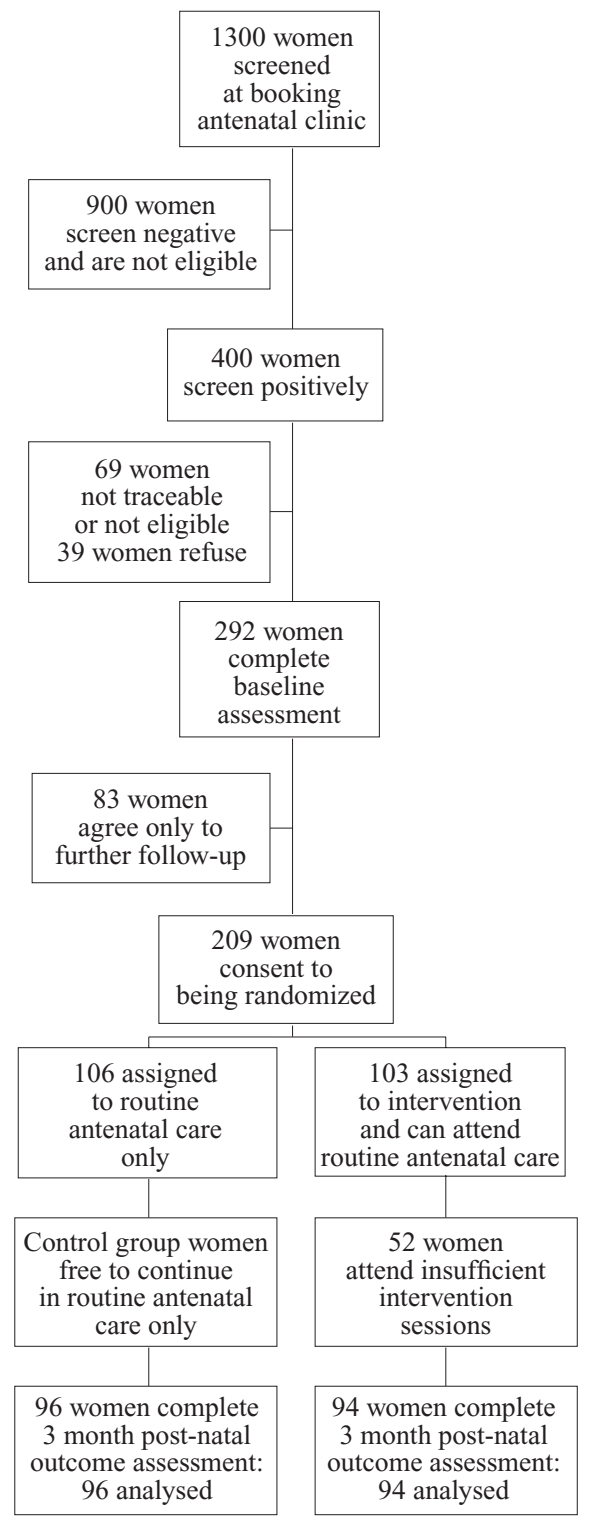

FIG. 2. Trial profile.

remaining 292 eligible women, 83 refused to be randomized (but agreed to be re-interviewed post-natally). Forty-two of the 94 intervention group women $(45 \%)$ who completed a 3-month outcome assessment were categorized as 'attenders': attending two or more sessions in addition to session 3 , which focused on postnatal depression. Thus, attendance at later sessions of each course dropped to four to six per group.
Table 1. Characteristics of two randomized groups at baseline interview

\begin{tabular}{lll}
\hline \hline & Treatment & Control \\
\hline Age (years) & & \\
Minimum & 16 & 17 \\
Median & 19 & 19 \\
Maximum & 38 & 38 \\
Stratification variables & & \\
GHQ-D, $N(\%)$ & & $24(23 \%)$ \\
$\quad$ High $\geqslant 3$ & $23(22 \%)$ & $82(77 \%)$ \\
Low $\leqslant 2$ & $80(78 \%)$ & $18(17 \%)$ \\
Social support, $N(\%)$ & $16(16 \%)$ & $88(83 \%)$ \\
$\quad$ High $\geqslant 6$ & $87(84 \%)$ & 77 \\
$\quad$ Low $\leqslant 5$ & 75 & 29 \\
Ethnic group, $N$ & 28 & 106 \\
$\quad$ European & & \\
Asian and other & 103 & \\
$\quad$ Base & & \\
\hline \hline
\end{tabular}

The percentage of cases of depression at 3 months in the intervention and control groups according to three definitions is set out in Table 2. According to intention-to-treat analyses there were no effects on depression on any of the three measures even after adjusting for the stratification variables used in randomization. The (non-significant) effect of the intervention was small: the odds ratio of 0.83 (Table 2) corresponds to an effect size of a $3 \%$ difference in the percentage of cases $(95 \% \mathrm{CI}-8 \%$ to $+14 \%)$ on the EPDS. Score differences for both symptom measures were also non-significant ( $t$ test). The third primary outcome measure, clinically assessed ICD-10 depressive disorder, also confirmed the absence of a treatment effect in logistic models and a survival analysis modelling time to onset. Analysis of the interviewer's records of which group she thought each respondent had been allocated to showed no difference from chance. To check whether the 34 women with missing outcome could have significantly altered the trial result we artificially set these womens' results to show, when compared with controls, total intervention success and total failure. In both of these sensitivity analyses the results remained non-significant.

Assignment to the intervention group had no impact on post-natal levels of social support (Table 3). There were also no significant differences between the groups in the proportion of respondents with risk factors present at baseline and at the 3 months outcome assessment, with one exception at outcome 
Table 2. Frequencies of and odds ratios for depression 3 months after childbirth by intention to treat

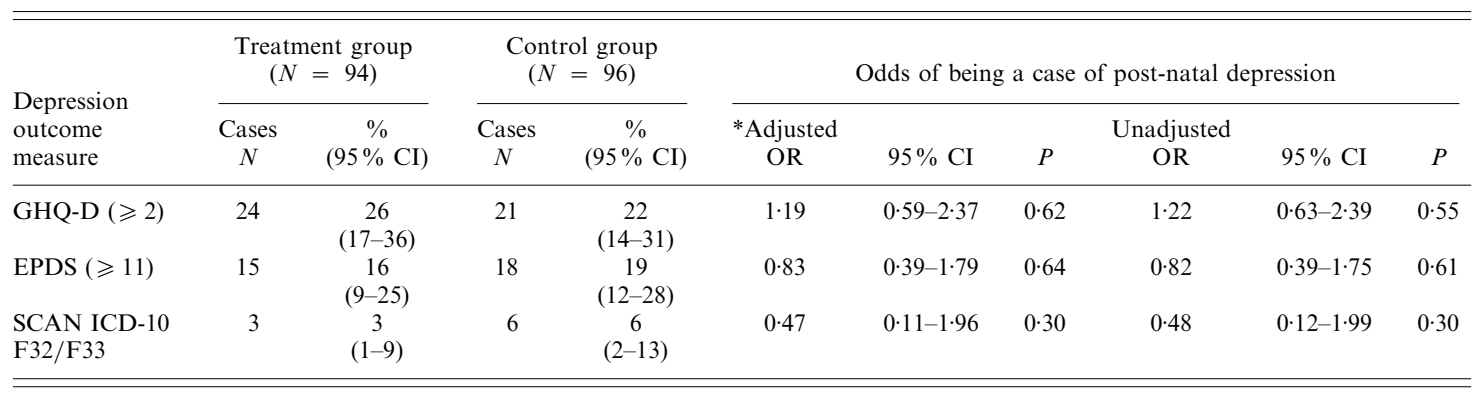

* Odds ratio adjusted for three stratification variables used in randomization by minimization: low support, severity of depression, ethnic group.

Table 3. Frequencies of and odds ratios for outcome risk factor variables 3 months post-natally

\begin{tabular}{|c|c|c|c|c|c|}
\hline \multirow[b]{2}{*}{ Variable } & \multicolumn{2}{|c|}{ Frequency } & \multirow[b]{2}{*}{ OR } & \multirow[b]{2}{*}{$95 \% \mathrm{CI}$} & \multirow[b]{2}{*}{$P$} \\
\hline & $\begin{array}{l}\text { Treatment } \\
\text { group }\end{array}$ & $\begin{array}{l}\text { Control } \\
\text { group }\end{array}$ & & & \\
\hline \multicolumn{6}{|l|}{ Poor social support } \\
\hline $\begin{array}{l}\text { Total number of named good friends } \\
\text { who had let her down recently }\end{array}$ & 1 & 0 & - & - & $0 \cdot 96$ \\
\hline $\begin{array}{l}\text { Total number of close relatives who } \\
\text { had let her down recently }\end{array}$ & 5 & 6 & $0 \cdot 84$ & $0 \cdot 25-2 \cdot 86$ & $0 \cdot 78$ \\
\hline Perceived poor social support at screening & 6 & 5 & $1 \cdot 24$ & $0 \cdot 37-4 \cdot 21$ & $0 \cdot 73$ \\
\hline $\begin{array}{l}\text { Combination of the three poor social } \\
\text { support variables above }\end{array}$ & 12 & 10 & $1 \cdot 26$ & $0 \cdot 52-3 \cdot 07$ & $0 \cdot 61$ \\
\hline \multicolumn{6}{|l|}{ Problem solving } \\
\hline High $v$. low confidence in ability to solve problems & 7 & 10 & $0 \cdot 69$ & $0 \cdot 25-1 \cdot 90$ & $0 \cdot 48$ \\
\hline Avoidant $v$. approaching style of solving problems & 45 & 28 & $2 \cdot 23$ & $1 \cdot 23-4 \cdot 06$ & $0 \cdot 009$ \\
\hline $\begin{array}{l}\text { High } v \text {. low belief in personal } \\
\text { control when solving problems }\end{array}$ & 47 & 45 & $1 \cdot 13$ & $0 \cdot 64-2 \cdot 00$ & $0 \cdot 67$ \\
\hline \multicolumn{6}{|l|}{ Locus of control } \\
\hline High $v$. low belief in powerful others influencing their life & 10 & 2 & $5 \cdot 59$ & $1 \cdot 19-26 \cdot 27$ & 0.03 \\
\hline $\begin{array}{l}\text { High } v \text {. low belief in chance or fate } \\
\text { influencing their life }\end{array}$ & 27 & 27 & $1 \cdot 03$ & $0.55-1.93$ & $0 \cdot 93$ \\
\hline $\begin{array}{l}\text { High } v \text {. low belief in internal } \\
\text { personal factors influencing their life }\end{array}$ & 45 & 47 & $0 \cdot 96$ & $0 \cdot 54-1.69$ & $0 \cdot 88$ \\
\hline \multicolumn{6}{|l|}{ Life events } \\
\hline $\begin{array}{l}\text { Occurrence of many } v \text {. few non- } \\
\text { pregnancy specific events including LTE }\end{array}$ & 42 & 36 & $1 \cdot 35$ & $0 \cdot 75-2 \cdot 40$ & $0 \cdot 31$ \\
\hline Many $v$. few pregnancy specific events occurring & 13 & 22 & $0 \cdot 54$ & $0 \cdot 25-1 \cdot 15$ & $0 \cdot 11$ \\
\hline Many $v$. few support threatening events occurring & 28 & 30 & 0.93 & $0 \cdot 50-1 \cdot 73$ & $0 \cdot 83$ \\
\hline Many $v$. few difficulties with ADL & 1 & 6 & $0 \cdot 16$ & $0 \cdot 02-1 \cdot 37$ & $0 \cdot 09$ \\
\hline High $v$. low dissatisfaction with housing & 2 & 4 & $0 \cdot 50$ & $0 \cdot 09-2 \cdot 80$ & $0 \cdot 43$ \\
\hline $\begin{array}{l}\text { Primary and secondary health service } \\
\text { contact since randomization }\end{array}$ & 13 & 11 & $1 \cdot 24$ & $0 \cdot 53-2.93$ & $0 \cdot 62$ \\
\hline Base ( $N$ for group) & 94 & 96 & & & \\
\hline
\end{tabular}

LTE, Life threatening events; ADL, Activities of Daily Living. 
(Table 3). Intervention group women were more than twice as likely to adopt an avoidantproblem-solving style $(P=0 \cdot 009)$. Using logistic modelling to adjust for this covariate at baseline did not alter the trial results.

The percentage of GHQ-D cases of depression did not differ significantly in a comparison of women who attended sufficient sessions (33\%; $N=42$ ) with those with less exposure to intervention ('non-attenders', $19 \% ; N=52$ ). The trend for women who attended the core elements of the intervention to have a greater likelihood of post-natal depression may be explained by a similar trend at baseline: $38 \%$ of attenders compared to $23 \%$ 'non-attenders' were depressed at baseline. We compared rates of depression at baseline and 3 months postnatally with estimates in screen positive Leicestershire women not involved in prevention evaluation (Brugha et al. 1998a): the proportion depressed appeared lower in trial participants.

\section{DISCUSSION}

This pragmatic randomized trial has demonstrated that assignment to the primary preventative, risk-reducing, antenatal intervention had no major impact on post-natal depression, and furthermore that this had no significant impact on the prevalence of the main risk factors for post-natal depression. Adjusted analyses taking account of baseline level of depression and other potential confounders, and sensitivity analyses required by a full intention to treat analysis that takes account of missing outcome data, confirmed the trial results. A high proportion $(55 \%)$ of women who consented to be randomized and participate in the intervention attended too few sessions to be likely to benefit. Nevertheless, there was no evidence that attenders benefited more than non-attenders.

A high proportion (72\%) of those identified in the population as eligible to participate agreed to do so. But, the internal validity of the trial may have suffered from the high proportion of those assigned to the intervention group receiving less than a theoretically sufficient critical exposure. However, such rates of adherence are the rule rather than the exception in routine practice (Wright, 1993) and in health promotion studies (van-Son et al. 1998). There are no grounds for believing that other services would achieve sufficiently high adherence rates unless a one-to-one home-based intervention was offered, at considerably greater cost.

Additional data collected showed that women who participated enjoyed the intervention and believed it to be beneficial (Wheatley \& Brugha, 1999). Session feedback indicated that the essential intervention components had been covered by the course leaders (Brugha, et al. $1998 b$; Wheatley \& Brugha, 1999). However, it is possible that the brief training organized for the course leaders and their lack of experience in structured psychological interventions may have caused shortcomings in delivery.

Two other antenatal prevention trials of brief interventions just completed in the Netherlands and Iowa seem to show a similar lack of impact on depression at 3 months post-natally (van-Son et al. 1998) and poor attendance rates (Gorman \& O'Hara, 1998). An 'early treatment' intervention carried out on high risk group women throughout the 12 week post-natal period of maximum risk (Brugha et al. 1998a) may prove more effective (Elliott et al. 1988). Some techniques included in PFP, when used by highly skilled therapists over longer time periods, benefit people with clinically significant symptoms (Brugha, 1995b). Our findings may point to a more general difficulty, in bringing about the modest changes in behaviour and cognition sought in this study quickly enough to achieve the prevention of less severe levels of depression post-natally. Until these problems are overcome, evidence of the efficacy of carer support for post-natal depression (Ray \& Hodnett, 1999) currently favours instead a policy of post-natal detection and intervention with established cases. In effect, for now at least, treatment is better than prevention.

Our intervention was designed to address risk factors directly through the individual (Mrazek \& Haggerty, 1994) rather than at a wider socioenvironmental level (Lewis et al. 1998) where population-wide interventions might be more effective and of general benefit (Rose, 1993). However, this failure to achieve desired improvements of individual level risk factors means that we have not tested the potential theoretical benefits of doing so. Longer-term follow-ups are needed because we do not know whether such interventions have delayed effects both on risk factors and on mental health. 
Before conducting further such randomized trials, novel interventions should be developed, incorporating techniques acceptable and accessible to the population at risk. For example, those drawn from effective educational techniques (Coates et al. 1992), such as the greater use of role-plays and of rewards for skills practised between meetings, could enhance effectiveness in augmenting social support. In line with theoretical prediction, such techniques must show preliminary evidence of potential effectiveness in reducing risk, as well as in achieving gains in mental health.

The power of our trial was sufficient only to detect major prevention effects, not small benefits, such as preventing $10 \%$ of cases of post-natal depression. Only a very large trial could resolve this. However, an examination of our $95 \%$ confidence intervals provides little encouragement or guidance for planning such trials.

In conclusion, we have shown that a novel antenatal intervention could be developed quickly and implemented in a routine healthcare setting but was not effective in reducing psychosocial risk factors or in preventing postnatal depression. At this stage, the lessons of our study provide essentially pragmatic and not theoretical information. On the basis of these findings commissioners of health promotion and prevention services targeted at the prevention of post-natal depression should not implement antenatal programmes on the lines of PFP in the expectation of substantial benefits. Further research is needed to demonstrate the feasibility and effectiveness of such methods. Expectations based on sincere beliefs in the supposed benefits of such short-term psychosocial approaches may be over optimistic.

The National Health Service Research and Development National Mental Health Programme and Leicestershire Mental Health Services NHS Trust provided funding.

\section{REFERENCES}

Barnett, B. E. W., Hanna, B. \& Parker, G. (1983). Life event scales for obstetric groups. Journal of Psychosomatic Research 27, 313-320.

Brugha, T. S. (1995a). Depression undertreatment: lost cohorts, lost opportunities? Psychological Medicine 25, 3-6.
Brugha, T. S. (1995b). Social Support and Psychiatric Disorder: Research Findings and Guidelines for Clinical Practice. Cambridge University Press: Cambridge.

Brugha, T.S. (1995c). Social support and psychiatric disorder: recommendations for clinical practice and research. Social Support and Psychiatric Disorder: Research Findings and Guidelines for Clinical Practice (ed. T. S. Brugha), pp. 295-334. Cambridge University Press: Cambridge.

Brugha, T.S. \& Cragg, D. (1990). The List of Threatening Experiences: the reliability and validity of a brief life events questionnaire. Acta Psychiatrica Scandinavica 82, 77-81.

Brugha, T., Bebbington, P., Tennant, C. \& Hurry, J. (1985). The List of Threatening Experiences: a subset of 12 life event categories with considerable long-term contextual threat: Psychological Medicine 15, 189-194.

Brugha, T. S., Sturt, E., MacCarthy, B., Potter, J., Wykes, T. \& Bebbington, P. E. (1987). The Interview Measure of Social Relationships: the description and evaluation of a survey instrument for assessing personal social resources. Social Psychiatry 22, 123-128.

Brugha, T. S., Sharp, H. M., Cooper, S. A., Weisender, C., Britto, D., Shinkwin, R., Sherrif, T. \& Kirwan, P. H. (1998a). The Leicester 500 Project. Social support and the development of postnatal depressive symptoms, a prospective cohort survey. Psychological Medicine 28, 63-79.

Brugha, T., Wheatley, S., Shapiro, D., Jones D. R., Taub, N. A., Friedman, T., Culverwell, A. \& Kirwan, P. H. (1998b). Prevention of postnatal depression by brief antenatal intervention. The development and evaluation by randomised controlled trial of a new psychosocial intervention. Unpublished report to the NHS Executive National R\&D programme, London.

Clarke, G. N., Hawkins, W., Murphy, M., Sheeber, L. B., Lewinsohn, P. M. \& Seeley, J. R. (1995). Targeted prevention of unipolar depressive disorder in an at-risk sample of high school adolescents: a randomized trial of a group cognitive intervention. Journal of the American Academy of Child and Adolescent Psychiatry 34, 312-321.

Coates, M., Leach, A., Lentell, H., Phillips, M. \& Scott, E. (1992). Open Teaching Toolkit: Effective Tutorials. The Open University: Milton Keynes.

Cooper, P. J., Campbell, E. A., Day, A., Kennerley, H. \& Bond, A. (1988). Non-psychotic psychiatric disorder after childbirth: a prospective study of prevalence, incidence, course and nature. British Journal of Psychiatry 152, 799-806.

Corcoran, C. (1997). The NCT. Modern Midwife 7, 34

Cox, D. R. (1972). Regression models and life tables (with discussion) Journal of the Royal Statistical Society 34, 187-220.

Cox, J. L., Holden, J. M. \& Sagovsky, R. (1987). Detection of postnatal depression. Development of the 10 item Edinburgh Postnatal Depression Scale. British Journal of Psychiatry 150, 782-786.

Cutrona, C. E. (1989). Ratings of social support by adolescents and adult informants: degree of correspondence and prediction of depressive symptoms. Journal of Personality and Social Psychology 57, 723-730.

Department of Health, (1999). National Service Frameworks for Mental Health. Modern Standards and Service Models. Department of Health: London.

Elliott, S. A., Sanjack, M. \& Leverton, T. J. (1988). Parents groups in pregnancy. A preventative intervention for postnatal depression? In Marshalling Social Support, (ed. B. H. Gottlieb), pp. 87-110. Sage: Beverly Hills.

Evans, S., Day, S. \& Royston, P. (1990). MINIM: A Program for Randomising Patients to Treatment Groups in Clinical Trials by the Method of Minimisation. Version 1.5. Guy's Hospital: London.

Gordon, R. E. \& Gordon, K. K. (1960). Social factors in prevention of post partum emotional adjustment. Obstetrics and Gynecology 15, $433-438$

L. L. Gorman \& M. W. O'Hara. (1998). Prevention of postpartum depression and adjustment difficulties in high risk women. Biennial Meeting of the Marce Society, Department of Psychology, University of Iowa, Iowa. 
Hawton, K., Salkovskis, P., Kirk, J. \& Clark, D. M. (1990). Cognitive Behaviour Therapy for Psychiatric Problems. Oxford University Press: Oxford.

Heppner, P. P. \& Petersen, C. H. (1982). The development and implications of a personal problem-solving inventory. Journal of Counselling Psychology 29, 66-75.

Holden, J. (1994). Can non-psychotic depression be prevented? In Perinatal Psychiatry. Use and Misuse of the Edinburgh Postnatal Depression Scale. (ed. J. Cox and J. Holden), pp. 54-81. Gaskell: London.

Kirkham, M. A. (1993). Two-year follow-up of skills training with mothers of children with disabilities. American Journal of Mental Retardation 97, 509-520.

Klerman, G. L. \& Weissman, M. M. (1992). The cause, morbidity and costs of depression. Archives of General Psychiatry 49, 831-834.

Labs, S. M. \& Wurtele, S. K. (1986). Fetal health locus of control scale: development and validation. Journal of Consulting and Clinical Psychology 54, 814-819.

Lewis, G., Bebbington, P., Brugha, T., Farrell, M., Gill, B., Jenkins, R. \& Meltzer, H. (1998). Socioeconomic status, standard of living and neurotic disorder. Lancet 352, 605-608.

Meltzer, H., Gill, B., Petticrew, M. \& Hinds, K. (eds.) (1995). Office of Population Censuses \& Surveys Social Survey Division. OPCS Surveys of Psychiatric Morbidity in Great Britain. Report 3. Economic Activity and Social Functioning of Adults with Psychiatric Disorders: OPCS Surveys of Psychiatric Morbidity in Great Britain. HMSO: London.

Mrazek, P. J. \& Haggerty, R. J. Editors: P. J. Mrazek \& R. J. Haggerty. (1994). Reducing Risks for Mental Disorders: Frontiers for Preventive Intervention Research. National Academy of Medicine: Washington, DC.

Murray, C. J. \& Lopez, A. D. (1997). Global mortality, disability, and the contribution of risk factors: Global Burden of Disease Study. Lancet 349, 1436-1442.

Murray, L., Fiori-Cowley, A., Hooper, R. \& Cooper, P. (1996). The impact of postnatal depression and associated adversity on early mother-infant interactions and later infant outcome. Child Development 67, 2512-2526.

O'Hara, M. W. \& Swain, A. M. (1996). Rates and risk of postpartum depression - a meta-analysis. International Review of Psychiatry $\mathbf{8}$, 37-54.

Parry, G. (1995). Social support processes and cognitive therapy. In Social Support and Psychiatric Disorder: Research Findings and Guidelines for Clinical Practice, (ed. T. S. Brugha), pp. 279-294. Cambridge University Press: Cambridge.

Paykel, E. S. \& Jenkins, R. (1994). Prevention in Psychiatry. Gaskell: London.
Paykel, E. S. \& Priest, R. G. (1992). Recognition and management of depression in general practice: consensus statement. British Medical Journal Clinical Research Edition 305, 1198-1202.

Paykel, E. S., Emms, E. M., Fletcher, J. \& Rassaby, E. S. (1980). Life events and social support in puerperal depression. British Journal of Psychiatry 136, 339-346.

Ray, K. L. \& Hodnett, E. D. (1999). Caregiver support for postpartum depression. In The Cochrane Library, Issue 4. Update Software: Oxford

Rose, G. (1993). Mental disorder and the strategies of prevention. Psychological Medicine 23, 553-555.

Stamp, G. E., Williams, A. S. \& Crowther, C. A. (1995). Evaluation of antenatal and postnatal support to overcome postnatal depression: a randomized, controlled trial. Birth 22, 138-143.

Surtees, P. G. \& Miller, P. M. (1990). The interval General Health Questionnaire. British Journal of Psychiatry 157, 686-693.

Van-Son, M. J. M., Verek, G. \& Pop, V. J. M. (1998). Prevention of postpartum depression in high-risk women. Biennial Meeting of the Marce Society, Department of Psychology, University of Iowa, Iowa.

Wells, K. B., Rogers, W., Burnam, M. A. \& Camp, P. (1993). Course of depression in patients with hypertension, myocardial infarction, or insulin-dependent diabetes. American Journal of Psychiatry 150, 632-638.

Wheatley, S. (1998). The Leicester Housing Schedule: Background and Questionnaire Format. Working paper, Section of Social and Epidemiological Psychiatry. Department of Psychiatry, University of Leicester, Leicester.

Wheatley, S. \& Brugha, T. S. (1999). Just because I like it doesn't mean it has to work: personal experience of an antenatal psychosocial intervention designed to prevent postnatal depression. International Journal of Mental Health Promotion 2, 26-31.

Wheatley, S. L., Culverwell, A., Brugha, T. S. \& Shapiro, D. A. (2000). Preparing for parenthood: background and development of a risk modifying intervention to prevent postnatal depression. Archives of Women's Mental Health (in the press).

Wing, J. K., Babor, T., Brugha, T., Burke, J., Cooper, J. E., Giel, R., Jablenski, A., Regier, D. \& Sartorius, N. (1990). SCAN. Schedules for Clinical Assessment in Neuropsychiatry. Archives of General Psychiatry 47, 589-593.

World Health Organization Division of Mental Health (1990). ICD10 Chapter V Mental and Behavioural Disorders (Including Disorders of Psychological Development): Diagnostic Criteria for Research (May 1990 Draft for Field Trials). World Health Organization: Geneva.

Wright, E. C. (1993). Non-compliance-or how many aunts has Matilda? Lancet 342, 909-913. 